ENSAYOS 



\title{
Juego de luces y otros motivos en “La danza clara” de José María Eguren
}

\author{
Sonia Luz Carrillo
}

\section{LA DANZA CLARA}

Es noche de azul oscuro

en la quinta iluminada

se ve multicolora

la danza clara.

Las parejas amantes

juveniles

con música de los sueños

ríen

Hay besos, harmonías

lentas escalas

y vuelan los danzarines

como fantasmas.

La núbil de la belleza

brilla 
como la rosa blanca

de la India;

ríe danzando

con el niño la Muerte

cano.

Publicado en 1929, en la edición de la Biblioteca Amauta, en la que además de Simbólicas y La canción de las figuras, aparece Sombra y el conjunto agrupado bajo el nombre de Rondinelas ${ }^{1}$, este poema -que integra la última sección- es probable que haya sido escrito pocos años antes. En él encontramos el rasgo señalado por Ricardo SilvaSantisteban como "austeridad estricta" capaz de "desmaterializar el paisaje" $^{2}$ a fin de entregarnos una poesía en la que luces y sombras esquivas construyen un mundo de puras esencias. "La danza clara" pone de manifiesto una vez más la total autonomía de la construcción estética. Poema en el que la intensificación del significante nos coloca ante un mensaje "indeterminado, sugerido, abstracto" ${ }^{3}$. Un poema de plena madurez humana y estética.

\section{El título: la danza clara}

El título anuncia movimiento suave y armonioso connotado en danza; también musicalidad, puesto que ésta se asocia rápidamente a sones. Con el aporte del adjetivo clara, se remarca el carácter de un mensaje que nos presenta un ambiente amable y distendido.

1 Al respecto cabe mencionar lo expuesto por Estuardo Núñez: "La edición AM-1929, además de las secciones Simbólicas y La canción de las figuras, incorporó dos nuevos libros antes no publicados, esto es, Sombra (con 26 poemas) y Rondinelas con 15 poemas". Núñez, Estuardo. José María Eguren. Poesías completas. Lima: Universidad Nacional Mayor de San Marcos. Patronato del Libro Universitario, 1961, Introducción, p. 29.

2 Silva-Santisteban, Ricardo. "Favila: Un poema hermético de Eguren”, en J.M.E. Aproximaciones y perspectivas. Lima: Universidad del Pacífico, 1977, p. 198.

3 Abril, Xavier. “José María Eguren, un poeta hermético", en Fanal 53. Lima, 1957, p. 24. 


\section{Primera estrofa: los grados de luz}

Desde los primeros versos Eguren, en uso de uno de sus recursos más constantes, nos hace transitar del azul oscuro de la noche a la quinta que emerge de la oscuridad, iluminada y de múltiples colores.

Como en una secuencia cinematográfica, pasamos de un plano general de oscuridad inquietante -luego de un movimiento de acercamiento o de mejor definición de lo que observamos- a un ambiente ameno y claro. Danza y claridad -que se producen en un tipo de edificación que connota casa amplia o de varios habitantes- se oponen a noche y oscuridad. Hay que señalar aquí que noche es uno de los motivos reiterados en Rondinelas ${ }^{4}$, y recordar que en uno de sus Motivos estéticos habla de ella como el momento en el que "Altas visiones se agigantan" y "van a las altas mansiones sugestivas y a las almenas fantasmales". También mencionará "su mundo de azules" de esta "farolera de la fantasía" una escena fantástica.

En torno a esta constante egureniana, dice Augusto Tamayo Vargas: "las 'Noches' están también llenas de lúgubres temores, de sombras de espíritus, de letales melancolías... bañadas de una luz romántica, con notas que hieren"'.

Y a propósito de la noche en la quinta, que nos trae limeñísimas reminiscencias, recordemos lo que opina Javier Sologuren acerca de la poesía de Eguren: "arte que descubre una de las fuentes de inspiración en el buido y sutil ámbito limeño. La ciudad cierne su clima -polvo y humedad deletéreos- y tradición -antañera conseja

4 "La utilización del motivo nocturno en la poesía de Eguren es progresiva, ningún título de Simbólicas menciona la noche y pocos poemas muestran el ambiente nocturno, mientras que en La canción de las figuras y en Sombra un $50 \%$ de los poemas tienen tema o título nocturno, que en Rondinelas llega a ser un 75\%". Gema Areta Marigó citando a Estuardo Núñez, en La poética de José María Eguren. Sevilla: Alfar, 1993, p. 115.

5 Obras completas. Lima: Banco de Crédito del Perú, 1997. Prólogo y notas de Ricardo Silva-Santisteban, pp. 239-240.

6 Tamayo Vargas, Augusto. Literatura peruana. Tomo III. Lima: Peisa, 1992, p. 678. 
de aparecidos y penas- en el verso de Eguren: cierto lacio ademán, cierta tristeza, cierto calofrío"7.

De otro lado, el azul, en sus variados tonos es uno de los colores identificados con la poesía lírica, y mencionado con insistencia por los modernistas desde el libro de Rubén Darío. Con la palabra "multicolora" estamos frente a uno de los recursos egurenianos señalado por Debarbieri: el recurso de la síntesis morfológica "palabra creada en función de significar con una sola el concepto de dos" ${ }^{\prime \prime}$. Diferencia sutil con "multicolor", adjetivo que, insertado en el verso, cobra fuerza de verbo. Podría decirse de aquello que tiene capacidad de proyectar múltiples colores.

\section{Segunda estrofa: los personajes}

Una vez presentado el escenario, claridad rodeada de azul oscuro, el poeta sugiere los primeros personajes de esta escena encantada: juveniles amantes. Y aporta dos datos sonoros. Si en la primera estrofa sólo mirábamos -primero desde cierta distancia, y luego más cercaahora escuchamos la música de los sueños y las risas. La alegría serena, el ambiente leve se hace más intenso. Confidencias, susurros, dulzuras a media voz.

Los amantes innominados y alegóricos -símbolo de vida, juventud y belleza- también de cierta fragilidad, se nos presentan como personajes del mundo onírico.

\section{Tercera estrofa: la danza y el sueño}

Las alusiones en este apartado insisten en la sonoridad. Las lentas escalas y las harmonías son los sonidos del sueño a la par que sus lentos movimientos. Luego emergen dos elementos visuales que parecieran

7 Sologuren, Javier. “Comento de Eguren”, en José María Eguren. Aproximaciones y perspectivas. Selección de Ricardo Silva-Santisteban. Lima: Universidad del Pacífico, 1997, p. 123.

8 Debarbieri, César. Los personajes en la poética de José María Eguren y otros textos. Lima: Universidad del Pacífico, 1990, p. 12. 
contradictorios. Los besos y el vuelo de los danzarines como fantasmas. La elección de este lexema aparece misterioso y presagiando peligro. La alegría es breve, frágil, está amenazada. Fantasma sugiere muerte, aunque también mundo extrasensorial. La exposición que venía apelando a fenómenos más o menos observables, aquí se torna nebulosa.

Eguren nos hace aceptar las reglas del juego. Estamos instalados en el misterioso mundo de los sueños y ahí es posible la danza con características de vuelo. Sin embargo, aquí encontramos lo señalado por Xavier Abril en el artículo antes citado, en torno al permanente antagonismo entre realidad y sueño.

\section{Cuarta estrofa: el peligro, el acabamiento}

La frescura adolescente, núbil, brilla como la rosa de la India -tributo a la corriente modernista y su preferencia por realidades exóticasremarcando la atmósfera despreocupada e inocente. Sin embargo algo acecha. Dos nuevos personajes hacen su aparición: La Muerte -así con mayúsculas- y el niño cano. ¿La brevedad de la edad de las danzas despreocupadas y dulces? ¿Noción de lo perecible presente desde la más tierna edad? ¿El yo poético cumple su función vidente?

Lo cierto es que el ambiente ameno y claro se ha visto trastornado. El horror de la Muerte se hace intenso con la imagen de ésta riendo mientras danza con el niño cano. Notable oposición la que se establece: niño, vida nueva, al lado de cano, símbolo de lo vetusto. El círculo se cierra, otra vez la oquedad, la oscuridad del miedo.

Respecto de la muerte, y citando especialmente esta estrofa de "La danza clara”, observa Javier Sologuren:

(hay una céltica familiaridad con ella) sopla y extiende su helor aun sobre la más temprana y amable vida, en esta breve estancia que trae a la memoria algún punzante y sarcástico grabado de Durero?

9 Sologuren, Javier. Op. cit., p. 123. 


\section{Las interpretaciones}

En una sumaria interpretación de Debarbieri, leemos:

Danza clara es un poema alegórico que se desarrolla entre las brumas del sueño y en danza de fantasmas.

La intención del poeta se centra en la pareja de la núbil de belleza y el niño de la Muerte, la cual encierra la alegoría de la vida y la muerte, ya que la primera "brilla/ como la rosa blanca", en tanto que el segundo es "cano"10.

A propósito de esta interpretación me parece oportuno mencionar los conceptos de Julio Ortega respecto de los riesgos de una interpretación que intente "racionalizar" los poemas de José María Eguren. El autor propone por ello lo que llama una "crítica interior", que parta de la idea de que un poema no significa sino sugiere, observación bastante obvia.

Para Julio Ortega, la capacidad sugerente se halla, en gran medida, basada en las oposiciones de dos grandes grupos léxicos: "...celeste, rubio, blonda, blanco, azul, alegre, risueña, leve, etc., se oponen a pena, difunto, oscuro, sombra, etc.". Líneas después señala que:

como cubriendo estos dos extremos hay otro grupo: ángeles, niñas, silfos, hada, vespertino, sueño, alba, opalino, brillan, antigua, galana, etc. Términos que parecieran resolver el conflicto que anuncian las oposiciones, pero que más bien las absorben en un mundo imaginario, fantástico ${ }^{11}$.

\section{Constantes de la poesía de Eguren presentes en "La danza clara"}

La lectura de "La danza clara" nos coloca frente a un conjunto de motivos recurrentes en la poesía de José María Eguren. Es decir, aquellas constantes que Debarbieri menciona, como: "El miedo, la noche, la muerte y el misterio"12.

Habría que agregar, sin duda, las constantes de sueño y juego de luces que hacen resaltar la oscuridad. En Rondinelas, por ejemplo,

10 Debarbieri, César. Op. cit., p. 120.

11 Ortega, Julio. Eguren. Antología. Prólogo, selección y notas de Julio Ortega. Lima: Editorial Universitaria, s/f, p. 8.

12 Debarbieri, César. Op. cit., p. 19. 
encontramos como título de un poema: "La viñeta obscura"; luego, en el poema "Vespertina" nos habla de la "crepuscular mariposa", la "animita bella de la selva oscura" y "las penumbras arcanas"; en "Patética" un "insondable amor/ llora en la penumbra" y veremos "un campo tenue de oscura luz" y en "la glacial penumbra un amor de antaño"; en "El romance de la noche florida" el "alma ríe en la marina obscura" y en otro verso se "aparta como a funestas brumas". En "Preludio" escuchamos "al fino soplo oscurecido / las campanas de la luna"; en "Antañera", "De un patio oscurecido / salen murciélagos"; en "Favila", "En la arena/ se ha bañado la sombra", "Aves de humo van a la penumbra" y "En la sombra ríen los triángulos". En "Véspera", "aletean las oscuras Causas". En "Los altares del camino", "la tierra obscura tiene un listón rosado"; y en "La canción del regreso", como vestigios de la noche, encontramos "Mariposas obscuras,/ muertas junto a los faroles".

En "La danza clara" nos hallamos una vez más frente a la poesía intensa de José María Eguren, capaz de ser, a la vez, leve y honda, construida sobre la base de las oposiciones vida-muerte, luz-sombra, vitalidad-acabamiento. Objeto estético plenamente autónomo, en el que el misterio al igual que la belleza "es tenue, impalpable, la azul neblina que tamiza los molinos de viento y los castillos almenados". Poesía hecha de sueño y sombra, donde habita la Belleza y eso "Lo sabrá el Poder que encarnan las fantasías y dramatiza la sombra ... cuando los sueños se vuelven perfumes y las almas sueños".

Para Eguren, poeta singular que inicia la renovación de la poesía peruana 13 , y rompe suavemente con los moldes establecidos, "Cada luz es nueva sombra", sin embargo, "Cuando se han obscurecido los matices amables, en las vísperas del camino negro, donde no se vuelve, herido de la vida aparece la niña de la cera simbólica ... con la luz de un sueño: la Esperanza"14.

13 José Carlos Mariátegui, en el capítulo dedicado a Eguren en su "Proceso a la literatura" había señalado: "Eguren se comporta siempre como un poeta puro. No escribe un solo verso de ocasión, un solo canto sobre medida. No se preocupa del gusto del público ni de la crítica", en 7 ensayos de interpretación de la realidad peruana. 1. a edición, 1928. Lima: Editora Amauta, undécima edición, p. 254.

14 Citas tomadas de los Motivos estéticos. "Metafísica de la belleza" y "La Esperanza". Reproducidos en Obras completas, pp. 214 y 234-235. 
